\title{
OS DESAFIOS DOCENTES E AS CONTRIBUIÇÕES DAS TECNOLOGIAS EDUCACIONAIS NO ENSINO E APRENDIZAGEM DE LÍNGUA INGLESA: CENÁRIOS CONTEMPORÂNEOS
}

\author{
LOS DESAFÍOS DE LOS MAESTROS Y LAS CONTRIBUCIONES DE LAS \\ TECNOLOGÍAS EDUCATIVAS EN LA ENSEÑANZA Y EL APRENDIZAJE DEL \\ IDIOMA INGLÉS: ESCENARIOS CONTEMPORÁNEOS
}

\section{THE TEACHERS' CHALLENGES AND THE CONTRIBUTIONS OF EDUCATIONAL TECHNOLOGIES IN THE TEACHING AND ENGLISH LANGUAGE LEARNING: CONTEMPORARY SCENARIOS}

\author{
Helenilson Ferreira de SOUSA ${ }^{1}$
}

Francisco Renato LIMA ${ }^{2}$

RESUMO: O presente artigo objetiva apresentar uma visão acerca dos desafios dos educadores e as contribuições das tecnologias educacionais no ensino de Língua Inglesa (LI) na contemporaneidade e suas implicações no contexto escolar. Busca-se demonstrar o papel do livro didático, a abordagem sobre as Tecnologias da Informação e da Comunicação (TICs) no ensino de LI, a avaliação e a necessidade de formação continuada de professores. A metodologia parte de uma abordagem qualitativa, aplicada por meio da pesquisa bibliográfica, fundamentada em autores como: Almeida; Valente (1997), Demo (1994/2008), Freire (1997), Hoffman (2003), Libâneo (2014), Moran (2000), Perrenoud (2000), entre outros. As reflexões apontam que as dificuldades dos docentes em introduzir essas ferramentas são devido a vários fatores, como: estrutura física do ambiente escolar, exaustiva carga horária do docente, ausência de formações específicas para o uso em sala de aula, falta de instrumentos pedagógicos, bem como a postura tradicional dos docentes e gestores.

PALAVRAS-CHAVE: Aprendizagem. Língua nglesa. Professor. Tecnologias educacionais.

I

RESUMEN: El presente artículo tiene como objetivo presentar una visión acerca de los desafios de los educadores y las contribuciones de las tecnologías educativas en la enseñanza de Lengua Inglesa (LI) en la contemporaneidad y sus implicaciones en el contexto escolar. Se busca demostrar el papel del libro didáctico, el enfoque sobre las Tecnologías de la Información y la Comunicación (TIC) en la enseñanza de LI, la evaluación y la necesidad de formación continuada de profesores. La metodología parte de un abordaje cualitativo, aplicado por medio de la investigación bibliográfica, fundamentada en autores como: Almeida; (1997), Demo (1994-2008), Freire (1997), Hoffman (2003), Libneo (2014), Moran

${ }^{1}$ Universidade Estadual do Piauí (UESPI), Teresina - PI - Brasil. Atua também, como professor de Língua Inglesa da Rede Estadual e Municipal de Ensino Básico. Licenciado em Biologia (UVA) e Letras Inglês (UESPI), Especialista em Gestão, Licenciamento e Auditoria Ambiental (UNOPAR). E-mail: helenilsonf2@hotmail.com

${ }^{2}$ Universidade Federal do Piauí (UFPI), Teresina - PI - Brasil. Professor de Leitura e Produção de Texto no ensino básico. Coordenador de disciplinas do Centro de Educação Aberta e a Distância (CEAD/UFPI). Mestre em Letras - Estudos da Linguagem (UFPI). ORCID: <https://orcid.org/0000-0002-1372-5444>. E-mail: fcorenatolima@hotmail.com 
(2000), Perrenoud (2000), entre otros. Las reflexiones apuntan que las dificultades de los docentes en introducir esas herramientas son debido a varios factores, como: estructura física del ambiente escolar, exhaustiva carga horaria del docente, ausencia de formaciones específicas para el uso en el aula, falta de instrumentos pedagógicos, bien como la postura tradicional de los docentes y gestores.

PALABRAS CLAVE: Aprendizaje. Lengua inglesa. Maestros. Tecnologías educativas.

ABSTRACT: The present article aims to present a vision about the teachers' challenges and the contributions of educational technologies in the English Language teaching (EL) in the contemporary world and its implications in the school context. It demonstrates the textbook role, the Information and Communication Technologies (ICT) approach in EL teaching, evaluation and need for continuing teacher training. The methodology is based on a qualitative approach, applied through bibliographic research, which is based on authors such as: Almeida; Valente (1997), Demo (1994/2008), Freire (1997), Hoffman (2003), Libâneo (2014), Moran (2000), Perrenoud (2000) and others. The reflections point out that the difficulties of teachers in introducing these tools are due to several factors, such as: physical structure of the school environment, exhaustive teacher workload, lack of specific classroom instruction, lack of pedagogical tools as the traditional posture of teachers and managers.

KEYWORDS: Teaching. English language. Teacher. Educational technologies.

\section{Introdução}

As tecnologias educacionais vêm ganhando espaço no cenário mundial, fato que pode ser associado às transformações ocorridas na sociedade capitalista contemporânea. E este novo cenário, também repercute na formação dos professores acerca do uso e manuseio correto de instrumentos digitais e midiáticos presentes no mundo tecnológico.

A visão dessas mudanças ocorre em escala mundial, em vista de inúmeros fatores sociais, culturais, econômicos, geográficos e políticos que proporcionaram os avanços tecnológicos no âmbito educacional. Esta difusão da informação trouxe um olhar diferenciado e também, a necessidade do surgimento de qualificações, a fim de aprender a conhecer e saber inserir essas ferramentas em sala de aula, com o intuito de promover o senso crítico e reflexivo de professores e alunos, como parte integrante do processo de ensino e aprendizagem.

No contexto educacional, são notórias as dificuldades que os professores de Língua Inglesa (LI) enfrentam para superar limitações metodológicas e conceituais na sua função de educador e formulador de opiniões. No entanto, eles vêm tentando acompanhar as descobertas 
tecnológicas ao longo da evolução da sociedade e através dessas ferramentas, promover uma formação crítica, pautada em uma base teórico-metodológica, que melhore a forma de repassar os conteúdos e construir aprendizagens significativas no ensino de línguas.

Ao tentarem introduzir esses recursos dentro da rotina pedagógica, os professores encontram barreiras que impossibilitam realizar inovações na prática. Essas limitações são justificadas pelo olhar de uma pedagogia tradicional, focada somente no uso de livros didáticos (LD), atividades de copiação, correção, exposição oral, postura que se repete durante todo o ano letivo, seja pela ausência de instrumentos tecnológicos educacionais ou mesmo pela própria postura dos gestores etc.

Mesmo reconhecendo as inúmeras possibilidades pedagógicas que as tecnologias educacionais possibilitam, é importante reconhecer que elas não irão resolver os problemas educacionais, os quais são muito mais profundos, considerando-se o contexto crítico e a natureza social, política, ideológica, econômica e cultural, que orientam o desenvolvimento e as progressões curriculares desenvolvidas na educação.

Para Moraes (1997, p. 53), “o simples acesso à tecnologia, em si, não é o aspecto mais importante, mas sim, a criação de novos ambientes de aprendizagem e de novas dinâmicas sociais a partir do uso dessas novas ferramentas", uma vez que será isso, que contribuirá para o desenvolvimento de novas práticas pedagógicas, baseadas em novas concepções de conhecimento, de alunos e de professores, transformando uma série de elementos que compõem o processo ensino e aprendizagem. Dessa forma, têm-se docentes e discentes, de fato inseridos, nos ambientes de aprendizagens das Tecnologias da Informação e da Comunicação (TICs).

Ademais, é preciso diminuir, particularmente, o construtivismo e o relativismo baseado somente na execução teórico-conceitual, sem ao menos o aluno perceber de forma subjetiva o mundo ao seu redor. A aproximação das aulas práticas deve ser muito cuidadosa, pois não se pode considerar a sala de aula como um simples espaço de expositivos e interativos, ao contrário deve-se mostrar a união entre teoria e prática, permitindo assim, a criação de um espaço escolar mais privilegiado e revestido de aprendizagem.

Henri Dieuzeide (1970) em seu estudo: "Tecnologia Educativa y desarrolho de la educación", distingue tecnologia da educação de tecnologia na educação. Para o autor, a primeira consiste na aplicação sistemática do conhecimento cientifico à facilitação do processo de aprendizagem, visando a aumentar seu rendimento; e a segunda, se orienta para os problemas de equipamentos, de mensagens e da sua incorporação, sem contestá-las. 
A partir disso, deve-se levar em consideração as seguintes questões: Qual a percepção do uso das tecnologias da educação? Quais as dificuldades que os docentes enfrentam ao introduzirem essas ferramentas em seu plano de aula? Qual sua contribuição para o processo de ensino e aprendizagem, se aplicadas de forma coerente?

Nesse contexto, a discussão proposta nesse estudo pauta-se na análise de perspectivas teóricas que discutem sobre a utilização das tecnologias educacionais dentro do contexto escolar e suas implicações no processo de ensino e aprendizagem; considerando-se as vantagens de utilizar esse mecanismo como construção reformuladora, que possibilita a reflexão sobre como os docentes estão lidando dentro das escolas, na medida em que as tecnologias vêm evoluindo. Com esse propósito, o trabalho lança mão de indagações teóricas, alinhavadas às condições de atuação educacional, vivenciada por professores.

Poucas discussões sobre a LI têm sido feitas, desde o início da implantação do ensino de Línguas Estrangeiras (LE) no currículo da educação brasileira. Nesse contexto de modificações e debates sobre os desafios enfrentados pelos docentes, surge uma questão fundamental para que ocorra um ensino de qualidade da disciplina de LI: o investimento na formação de professores, pois os profissionais desta área necessitam urgentemente, de um processo formativo que os levem a superar os desafios enfrentados nas aulas, e assim, possam oferecer contribuições às práticas, que atendam às necessidades de aprendizagens dos discentes.

Na estruturação das idéias aqui apresentadas, recorre-se a diversos autores, dentre eles: Almeida; Valente (1997), Demo (1994/2008), Freire (1997), Hoffman (2003), Libâneo (2014), Moran (2000), Perrenoud (2000), entre outros, os quais ajudam a melhor explicitar os desafios docentes e as contribuições das tecnologias educacionais no ensino e aprendizagem de LI na contemporaneidade.

Ainda para uma melhor compreensão e discussão da temática, o texto distribui-se de maneira lógica, começando por alguns recortes sobre práticas educativas e tecnologias no ensino e aprendizagem de LI; em seguida, estabelece as possíveis relações entre o livro didático e as tecnologias educacionais; depois, os métodos de ensino; e conclui-se apontando reflexões sobre a formação contínua do professor de Letras/Inglês na contemporaneidade.

Os desafios dos professores: uma abordagem sobre práticas educativas e tecnológicas no ensino e aprendizagem de Língua Inglesa (LI) 
Os desafios de se manter um processo de comunicação na LI se dão pela predominância de inúmeros fatores como: dificuldades na formação, problemas sociais, sobrecarga de professores (que, muitas vezes, lecionam outras disciplinas, como Língua Portuguesa), a questão física das escolas, superlotação (que dificulta a aprendizagem dos discentes), carência ou a inadequação de materiais didáticos e recursos tecnológicos e a falta de oportunidades para conversar em Inglês. Além disso, é importante destacar uma reflexão sobre os livros didáticos, pois embora alguns estejam disponíveis, apresentam um nível avançado em relação ao conhecimento dos alunos.

Segundo um estudo realizado em 2013, pelo Instituto de Pesquisas e Plano (CDE) para o British Council (2015), sobre o ensino de Inglês na educação pública brasileira, demonstrou em primeiro lugar, através de pesquisas com os professores, que um dos principais problemas no ensino da disciplina está relacionado à falta de recursos didáticos e logo, a falta de recursos tecnológicos.

Aprender uma segunda língua é buscar diferentes formas de comunicar-se, é agir autonomamente na sociedade, por isso as instituições de ensino devem promover meios que possibilitem a expansão dos conhecimentos de mundo do aluno, sem que sua individualidade seja desrespeitada, incluindo-o dentro das quatro habilidades linguísticas: Reading, Writing, Listening e Speaking (ler, escrever, ouvir e falar). Aprender todas elas, torna-se essencial para a formação e desenvolvimento do discente como um cidadão crítico e reflexivo.

Uma análise qualitativa sobre os desafios enfrentados nessa disciplina aponta que é necessário ratificar que os professores de Letras/Inglês não são preparados nas universidades, no que se refere a questões metodológicas para trabalharem o Speaking nas aulas e quando são, não têm a parte prática. Esse fato chama atenção, pois formar um docente requer a articulação de dois componentes curriculares destacados por Reinaldo (2003), que são o conhecimento teórico (domínio de conhecimento do objeto linguagem) e o conhecimento de ensino e de pesquisa sobre ensino (desenvolvimento da habilidade de ensino e o conhecimento de pesquisa sobre ensino-aprendizagem na área da linguagem).

É nítida a falta de preocupação das instituições de ensino em prepararem os docentes para promoverem meios de abordagens comunicativas, conforme propõem os Parâmetros Curriculares Nacionais do ensino de Língua Inglesa (PCNs) (BRASIL, 1997). Tal problemática é o que acarreta a própria frustração de muitos educadores em não conseguirem manter um processo de comunicação na sua língua de formação e até mesmo, não terem com quem manter trocas de ideias com colegas de área. Sobre essa questão, recorre-se a Demo (2008, p. 17) quando destaca que: 
Toda proposta que investe na introdução das TICs na escola só pode dar certo passando pelas mãos dos professores. O que transforma tecnologia em aprendizagem, não é a máquina, o programa eletrônico, o software, mas o professor, em especial em sua condição socrática.

Também, há de se destacar que, os meios tecnológicos, que ainda são limitados a uma massa da sociedade capitalista. Somente a partir do momento em que eles ganharem espaço dentro do ambiente escolar, começarão a ser incorporados ao ensino, de forma dinâmica e produtiva, constituindo-se como instrumentos de aprendizagem, com objetivo de diminuir a exclusão social. Assim, de acordo com Almeida; Valente (1997, p. 12), o emprego das tecnologias da informação e comunicação "impõe mudanças nos métodos de trabalho dos professores, gerando modificações no funcionamento das instituições e no sistema educativo."

As tecnologias educacionais, como: computadores, vídeos, apps, softwares, podcasts, games, áudios etc., favorecem a ampliação das possibilidades de construção de sentidos, mantendo um elo no processo de comunicação, além de ratificarem os objetivos explícitos dos PCNs (BRASIL, 1997). Dessa forma, apóia-se a necessidade de educadores letrados digitalmente, que conforme Vallin (2007, s/p), isso permite:

- Desfrutar de programas e softwares que atraem a atenção do aluno provocando a interatividade, participação e interesse do aprendiz;

- Exercitar a criatividade através da mescla de softwares de texto, apresentação, vídeo, áudio, imagens e links;

- Instigar a investigação através da utilização de sites de busca, bibliotecas virtuais e indicações bibliográficas encontradas na internet;

- Acesso a informações de ontem e de hoje que passam por frequentes atualizações;

- Construir e compartilhar conhecimentos através de enciclopédias on-line, livres e colaborativas;

- Facilidade oferecida por editores de texto que disponibilizam editoração e correção eletrônicas;

- Dicionários virtuais que torna a consulta mais prática e contínua;

- Conteúdos acessados com maior facilidade através de comandos que permitem especificar palavras ou expressões;

- Acesso a um determinado conteúdo através de um clique;

- Estruturar apresentações com mapas conceituais, imagens, sons, textos, vídeos e hyperlinks;

- Comunicar, interagir, trocar experiência e exercitar a coletividade através de fóruns de discussão, salas de bate-papo e listas de discussão;

- Facilidade e agilidade no intercâmbio de informações através do e-mail.

Diante dessas possibilidades, situa-se o letramento digital como um processo cuja expansão está se tornando cada vez mais necessária em nosso momento atual, marcado irreversivelmente por mudanças, onde as TICs ocupam espaços em todos os setores da 
sociedade. Não há como deixar de lado a questão de que o não domínio das linguagens digitais já está gerando um novo tipo de excluído: o digital.

Para que o sujeito seja considerado um letrado digital, primeiramente é preciso que ele seja letrado em relação ao seu idioma, possuindo, dessa forma, o domínio dos códigos de leitura e escrita vigentes em sua sociedade para que, a partir deles, possa ter condições de manusear as TICs e fazer um uso intencional, de modo a explorar as potencialidades que possuem dentro dos ambientes escolares.

Numa perspectiva interativa da leitura, escrita, audição e oralidade, os discentes devem ter diferentes instrumentos para a compreensão das informações apresentadas sobre os conteúdos durantes as aulas, e os professores são os principais responsáveis por realizar essas práticas, mantendo assim um elo entre a o ensino e tecnologia.

Em vista disto, destacam-se "empecilhos" para a implantação dentro do contexto escolar, como a postura tradicional de diretores, coordenadores, pais e professores. Além disso, os professores que fazem uso das novas tecnologias educacionais em sala de aula são taxados de "preguiçosos". Porém, é preciso considerar ainda outro fator: um grande número de professores que atuam hoje nesse cenário mediado pelas TICs, não teve essa orientação teórico-epistemológica no período de sua formação inicial, na universidade; e também, não investiram nessa área através de cursos de formação continuada, como especialização, mestrado e doutorado, e isso gera uma confluência entre saberes formativos e a necessidade de atender as exigências da prática pedagógica do ensino de LI.

Desde a implantação da Lei de Diretrizes e Base da Educação Nacional, LDB nº. 9.394/96, o ensino brasileiro se depara com uma verdadeira revolução na gestão da escola e da figura do gestor escolar, especificando as inúmeras responsabilidades, competências e habilidades exigidas para uma atuação administrativa, pedagógica e comunitária a partir dos princípios de gestão democrática no âmbito da escola pública.

Se levarmos em conta as leis, a gestão democrática acontece de fato em algumas escolas do país. Entretanto, muitos cargos tornam-se favores políticos, e por isso, vários gestores que estão dentro das instituições de ensino público conservam metodologias tradicionais e em boa parte, barram as práticas educativas dos professores quando o assunto são tecnologias educacionais, até mesmo, pelo fato, de também, não saberem lidar com a linguagem das TICs. Assim, Libâneo (2014, p. 21) reforça que:

Instituições sociais como as escolas pressupõem objetivos que deem sentido às ações educativas levadas a efeito frente a demandas sociais. Os objetivos determinam o tipo de sujeito a ser educado, os conteúdos a serem ensinados 
e aprendidos, os valores a serem formados, as práticas de organização da escola, o perfil profissional dos professores.

Dessa forma, a gestão escolar tem um árduo papel de planejar, liderar, promover iniciativas de criação de espaços e clima de reflexão, a fim de transformar as salas de aula em espaços de mobilização da competência e do envolvimento e experimentação das pessoas coletivamente para que, por sua participação ativa e competente, promovam a realização dos objetivos educacionais. De acordo com Almeida; Rubim (2004, p. 2-3),

O envolvimento dos gestores escolares na articulação dos diferentes segmentos da comunidade escolar, na liderança do processo de inserção das TIC na escola em seus âmbitos administrativo e pedagógico e, ainda, na criação de condições para a formação continuada e em serviço dos seus profissionais, pode contribuir e significativamente para os processos de transformação da escola em um articulador e produtor de conhecimentos compartilhados.

Para que isso ocorra, é preciso que haja um compromisso e um envolvimento dos gestores escolares no processo de formação continuada, voltada para o uso das novas tecnologias e mídias na educação. São os gestores uns dos principais responsáveis para que os novos recursos tecnológicos façam parte do cotidiano da escola.

Assim, cabe a gestão, aliada ao profissional que representa o ofício da docência, o professor, explorar todos os meios e espaços a favor do principal objetivo da educação, que é, segundo a concepção clássica de Piaget (1970, p. 28):

[...] criar homens que sejam capazes de fazer coisas novas e não simplesmente repetir o que outras gerações fizeram; homens que sejam criativos, inventores e descobridores; o segundo objetivo é formar mentes que possam ser críticas, que possam analisar e não aceitar tudo que lhes é oferecido.

Portanto, ao discutir sobre o ensino de LI no Brasil, é preciso urgentemente, a injeção de formações continuadas direcionadas aos docentes da área, bem como apoio de recursos didáticos para que as aulas aconteçam de maneira que os discentes consigam compreender os quatros habilidades, além de cursos de conversações para os professores da rede pública e nos próprios cursos de formação de professores nas universidades e faculdades, investir e "padronizar" os currículos, dando suporte aos professores de Inglês. Suporte este, em recursos tecnológicos e em formações específicas que busquem amenizar a situação do ensino de LE das escolas públicas. 


\title{
O Livro Didático (LD) de Língua Inglesa (LI): herói ou vilão no ensino- aprendizagem frente às novas tecnologias educacionais?
}

A relação entre as tecnologias e o ensino gera cada vez mais debates entre esses dois universos diferentes, embora não opostos, pois envolvem uma parte de tradição e a outra parte de contemporaneidade, que na prática, pode ser visualizada na articulação entre os LD e as novas tecnologias.

O LD é um veículo de comunicação que retrata a cultura por meio de conhecimentos e ideais. Sobre sua utilização no ensino de LI, há inúmeras discussões, tornando-se material e objeto de dissertações e teses em universidades (por exemplo: COSTA, 2016; FONTENELE, 2005; LEITE, 2003; TILIO, 2006). Já as tecnologias educacionais são os equipamentos digitais, a sistematização dos princípios científicos da teoria da comunicação com diversas ciências e suas aplicações na educação.

A própria literatura (CORACINI, 1999) descreve algumas metáforas que "retratam" as relações entre os $\mathrm{LD}$ das diversas áreas e os professores, mencionando que alguns educadores o empregam como uma Bíblia.

Em relação ao uso do LD, pode-se exemplificar algumas formas de como o educador é visto quando faz uso dele para todos os fins na disciplina, são elas: o aluno-professor, que tem a visão do livro como um companheiro e salvador nas suas regências, sendo um instrumento único utilizado nas aulas; o professor-pesquisador, que utiliza o livro como forma de instrumentalização, embora o graduado (ando) seja hábil em pesquisas e comunicações; e o aluno-aluno, que tem o livro didático como um recurso metodológico para o ensino de LI (DIONÍSIO, 2002).

Com base nisso, entre as habilidades a serem adquiridas durante os quatro anos do Ensino Fundamental, os PCNs (BRASIL, 1997, p. 66-67) destacam a necessidade de:

\begin{abstract}
Vivenciar uma experiência de comunicação humana, pelo uso de uma língua estrangeira, no que se refere a novas maneiras de se expressar e de ver o mundo, refletindo sobre os costumes ou maneiras de agir e interagir e as visões de seu próprio mundo, possibilitando maior entendimento de um mundo plural e de seu próprio papel como cidadão de seu país e do mundo.
\end{abstract}

É evidente que o livro é uma peça fundamental no processo de ensino e aprendizagem. Embora nos PCNs defendam a comunicação humana no ensino de LI como forma de expressão no mundo, percebemos que essa realidade é controversa, quando partimos de uma análise mais crítica sobre a situação educacional do ensino de Inglês no Brasil, principalmente quando o LD torna-se o único recurso metodológico utilizado pela maioria dos professores. 
Os LD adotados nas instituições de ensino são diferentes e a maior parte deles, traz os conteúdos e os CD- Rom, usados para o Listening, com níveis bem avançados. Diante disso, o educador tem que levantar um diagnóstico do grau de dificuldade deste, e um diagnóstico dos discentes sobre a disciplina e nisso, orientá-los em alguns aspectos para que compreendam os conteúdos ensinados.

Grande parte dos livros traz metodologias de Reading, Writing e Listening, entretanto a habilidade de Speaking é subtendida implicitamente, e por isso, o professor deve arcar e planejá-las para que aconteçam. No entanto, o educador diante dos desafios enfrentados na sua formação, emprega o uso apenas das três habilidades, pois não foi preparado para promover a abordagem comunicativa nas aulas.

Apesar disso, é preciso considerar posturas contrárias as situações citadas acima, pois mesmo diante das dificuldades apresentadas pelo sistema, alguns professores vão além, e inovam em suas práticas, através de uso de questionários escritos ou orais sobre aquilo que foi lido no LD, como por exemplo, perguntam aos educandos sobre as palavras transparentes, o enredo da história lida, de que se trata o cartaz publicitário, a receita, como são os personagens, ou se gostam ou não do que leram, quais as palavras que conseguiram ouvir, quais os significados, se conseguem pronunciar alguma ou fazer alguma pergunta em Inglês etc.

Desse modo, o LD e as tecnologias ganham significação para o processo de ensino e aprendizagem, quando articulados e utilizados dentro do ambiente escolar. Esses instrumentos possibilitam qualidade e melhoria para o professor lidar com diversas situações que desenvolvam as habilidades previstas para a disciplina. Assim, para que as tecnologias educacionais sejam consideradas instrumentos de busca da relevância na educação é essencial que, continuamente seja colocada questões relativas como, por exemplo: Para quem? Para que? E por que de sua contribuição à análise e soluções dos problemas educacionais do país?

Os métodos de ensino de Língua Estrangeira (LE) nas escolas: contribuições das Tecnologias da Informação e da Comunicação (TICs) nas avaliações de aprendizagem nas habilidades de Reading, Speaking, Writing e Listening

As escolas concentram-se no fato de lidarem com tecnologias com o objetivo principal de "[...] propiciar condições para que o aluno aprenda a buscar informações e saiba usá-las ao invés de recebê-las e memorizá-las, esquecendo rapidamente” (BRITO; PURIFICAÇÃO, 2006, p. 79). Corroborando com isso, Demo (1994, p. 100) também aponta que: 
As escolas são lugares de "decoreba" onde o aluno tangido para a domesticação, por vezes, internaliza coisas, junta na cabeça um monte de informações, aprende pedaços do conhecimento, mas não os juntam, sistematiza, questiona, reconstrói, porque o próprio professor não "sabe fazer isso".

Quanto à reflexão do autor, pode-se destacar a questão do writing, quando aplicado demasiadamente nas escolas públicas, em situações que os alunos, nos dias de avaliações, estudam aqueles determinados conteúdos como forma de "decorar" assuntos, muitas vezes, gramaticais utilizados somente na prova, simplesmente como um ato de responder, mas não sabem como usá-los na comunicação dentro e forma da escola.

Não é à toa que repetitivamente eles se deparam com o verbo to be durante todo Ensino Fundamental II, prosseguindo ao Ensino Médio, quando estudam novamente, porém, ainda sem saber como utilizá-los nas situações diárias, e muitos, nem mesmo conhecem a tradução. Ilustrando essa questão, cita-se Moran et al (2000, p. 17-18) quando destaca que:

As mudanças na educação dependem também dos alunos. Alunos curiosos e motivados facilitam enormemente o processo, estimulam as melhores qualidades do professor, tornam-se interlocutores lúcidos e parceiros de caminhada do professor-educador. Alunos motivados aprendem e ensinam, avançam mais, ajudam o professor a ajudá-los melhor. Alunos que provêm de famílias abertas, que apoiam as mudanças, que estimulam afetivamente os filhos, que desenvolvem ambientes culturalmente ricos, aprendem mais rapidamente, crescem mais confiantes e se tornam pessoas mais produtivas.

É preciso motivar, estimular e enriquecer a caminhada do educador com o uso de recursos precisos ao ensino, a fim de criar práticas diversas e avaliar o aluno de forma que não gere essa situação (DEMO, 1994). É essencial que as habilidades de LI tornem base do processo avaliativo, e este também não seja praticado apenas de forma somativa, através da atribuição de nota, de modo quantitativo.

O processo avaliativo de LI é bem tradicional. O professor utiliza pelo menos duas habilidades, Listening e Reading, mas na maior parte, faz uso exclusivamente do Writing, através do método gramatical, que facilita o trabalho. Esse método interfere diretamente no processo avaliativo e no ensino e aprendizagem, pois dependendo dos instrumentos e da forma como são aplicados, tem-se um resultado e ações estritamente tradicionais, quando o objetivo é inserir os alunos nos processos de comunicação.

De acordo com Firth (1929) apud Lima; Silva Filho (2013, p. 13), “a língua deve ser vista como parte do processo social, pois seu papel é de interação entre as pessoas". Assim, a abordagem comunicativa por uso das tecnologias é significativamente importante, pois coloca 
os educandos e educadores como sujeitos participantes da construção dos conhecimentos, e os professores têm uma visão mais ampla do desenvolvimento do processo avaliativo, podendo, dependendo da situação, planejar ações de intervenção. Mas como as tecnologias entram no contexto do ato avaliativo?

Segundo Perrenoud (2000, p. 139) "as novas tecnologias podem reforçar a contribuição dos trabalhos pedagógicos e didáticos contemporâneos, pois permitem que sejam criadas situações de aprendizagem ricas, complexas, diversificada". O autor demonstra que, estes recursos tecnológicos, planejados e aplicados nas escolas, bem como os resultados por meio deles alcançados pelos alunos, historicamente, contribuem para uma prática de transformação e de emancipação dos discentes.

Com relação a isso, Hoffman (2003, p. 16) afirma que:

O caminho para o desenvolvimento é uma educação igualitária, que acolha os filhos dessa geração em conflito e projete essa geração no futuro, conscientes do seu papel numa possível transformação. Se essa criança desde logo for considerada como de um futuro impossível, não terá nem um tempo justo de provar o quanto poderemos contar com ela.

A autora defende que o professor deve acolher a sua clientela por meio do processo de avaliação, visando resultados que possibilitem reestruturar o trabalho pedagógico. Aliado a isso, a aplicação das tecnologias educacionais deve ocorrer em salas de aulas, com fins de possibilitar a continuidade do conteúdo ou retorno do ensino, com metodologias diferenciadas, que coloquem os discentes em condições concretas de aprender os conhecimentos construídos socialmente.

Esse é um momento em que podemos acompanhar de perto as falhas e os avanços que estão acontecendo como, por exemplo, no instante em que um texto é apresentado aos sujeitos, parte deles não compreende o vocabulário e é nesse instante que o professor deve fazer uso de "peças" demonstrativas, introduzir os recursos tecnológicos e associativas, de modo a reforçar a aprendizagem.

A avaliação de LI é uma temática ainda pouca discutida no Brasil em relação às demais disciplinas. Precisa-se de estudos que sirvam de base para melhorar a qualidade dessa prática, a fim de que seja levada mais a sério a necessidade de indicadores, de meios tecnológicos e internet que cheguem não somente na zona urbana, mas também, na zona rural, capacitações e formações contínuas que atenda as gritantes necessidades dos professores de LE. 
A falta de estudos sobre a avaliação no ensino de LE dificulta a padronização, a implementação de processos de avaliação e até mesmo, impossibilita a mensuração de indicadores no ensino em relação a outras áreas que possuem exames específicos, por exemplo, a prova SAEB e até mesmo, o próprio Exame Nacional do Ensino Médio (ENEM), que traz um grande número de questões de outras disciplinas e apenas cinco de Inglês.

\section{O educador e a formação continuada na contemporaneidade}

A questão do ensino é descrita frequentemente como um problema relacionado a deficiências na formação dos professores, desigualdades sociais e carência da escola. Segundo Libâneo (2014, p. 227):

O termo formação continuada vem acompanhado de outro, a formação inicial. A formação inicial refere-se ao ensino de conhecimentos teóricos e práticos destinados à formação profissional, completados por estágios. A formação continuada é o prolongamento da formação inicial, visando o aperfeiçoamento profissional teórico e prático no próprio contexto de trabalho e o desenvolvimento de uma cultura geral mais ampla, para além do exercício profissional.

Podem ser destacados inúmeros fatores que levam o fracasso escolar, dentre eles, estão os chamados cursos de "imitação". Estes são feitos antes ou após a graduação, onde, muitas vezes, os professores participam apenas por interesse de receber um certificado de nível superior ou com propósito de aumento salarial, a ponto de esquecerem-se de dedicar-se ativamente nos progressos do curso.

Conforme Demo (2008, p. 03), "todo processo de aprendizagem requer a condição de sujeito participativo, envolvido, motivado, na posição ativa de desconstrução e reconstrução de conhecimento e informação, jamais passiva, consumista, submissa”. Em complemento a essa ideia, Freire (1997, p. 20), destaca que "a educação e a formação permanente se fundem". Essa fusão possibilita superações de problemas nas diversas áreas, e está relacionada a uma graduação mais "participativa" e ofertas de curso de educação continuada ativa, com habilidades de criar e recriar práticas de maneira que os alunos possam reformular os conhecimentos adquiridos, criando seus próprios conceitos diante da realidade da sociedade e assim, passarem a entender o processo pedagógico. Para Libâneo (2014, p. 227):

[...] a formação continuada pode possibilitar a reflexividade e a mudança nas práticas docentes, ajudando os professores a tomarem consciência das suas dificuldades, compreendendo-as e elaborando formas de enfrentá-las. De 
fato, não basta saber sobre as dificuldades da profissão, é preciso refletir sobre elas e buscar soluções, de preferência, mediante ações coletivas.

É conveniente pontuar que, a Resolução CNE/CP (19/02/2002), sobre as Diretrizes Curriculares Nacionais para a Formação de Professores da Educação Básica, em nível traz em seu Art. $2^{\circ}$, inciso VI, que os currículos devem preparar o professor para "o uso de tecnologias da informação e da comunicação e de metodologias, estratégias e materiais de apoio inovadores"; e ainda em seu Art. $7^{\circ}$, especificamente no parágrafo IV: "as instituições de formação trabalharão em interação sistemática com as escolas de educação básica, desenvolvendo projetos de formação compartilhados”.

De acordo com Paiva (2006, p. 48):

Os professores reclamam que a escola regular era fraca, que as aulas eram ministradas em português; [...] que o conteúdo se restringia à gramática, ao vocabulário e verbo "to be" e que não havia conversação, "listening" ou preocupação com a pronúncia. [...] Mesmo quando se referem à universidade alguns reclamam que as aulas eram em português e que não havia aula de conversação [...].

Os desafios enfrentados pelos professores/educadores e apontados por este artigo supõe-se que o país só alcançará um êxito no ensino de LI quando houver um forte investimento na formação desses professores, na estrutura física das instituições de ensino, em recursos pedagógicos, na estruturação acadêmica da universidade, na disponibilização de capacitações e na formação contínuas de qualidade para que os professores possam desenvolver atitudes, valores morais e éticos em seus alunos, de modo a compreender o verdadeiro objetivo da disciplina de Inglês.

Mas para que logre resultados positivos no ensino de LE, tanto qualitativamente, como quantitativamente, é essencial, a injeção de formação e a própria valorização do profissional docente, como o princípio primeiro para a verdadeira inclusão e o reconhecimento do professor de Letras/Inglês, que sempre teve sua área esquecida por parte de governantes e instituições. Essa valorização, por meio de formações exclusivas e específica da área, torna-se um dos pilares para ajudar na resolução dos problemas da educação brasileira e quando aborda-se a questão de cursos de formação continuada no ensino de Inglês, destaca-se exclusivamente, os cursos de metodologias, sendo um curso de conversação a principal busca dos educadores, porém, poucos ou quase nenhum, conseguem arcar com o custo quando procuram escolas de ensino.

Em conformidade com essas teorias, pode se compreender que a formação contínua na contemporaneidade para o professor de LI inclui dimensões, tais como: a valorização social, a 
inclusão dos professores e alunos, as percepções e conhecimentos no ensino de LI e o desenvolvimento de habilidades que envolva as várias dimensões do processo de comunicação dos sujeitos.

\section{Considerações finais}

São visíveis os desafios dos educadores na contemporaneidade, principalmente quando se aborda a formação do sujeito em Letras/Inglês, confrontado com a habilidade de Speaking, a falta de formações contínuas para os professores da disciplina de LI, as barreiras postas por gestores tradicionais, a carência de recursos tecnológicos que alcancem todos as áreas, o método tradicional de avaliação que ocorre por meio de testes de Writing, a necessidade de cursos de informática para os educadores. Todas esses, são problemáticas enfrentadas pelos docentes e que devem ter uma atenção maior por parte dos governantes e das instituições de ensino.

Acredita-se que, as suscitações, os questionamentos e as propostas teóricas - mas ainda assim construídas sobre experiências práticas - apresentadas neste artigo, possam contribuir para a abertura de espaços e discussões a respeito do ensino de LI nas escolas públicas do Brasil, contribuindo para um replanejamento das práticas educativas, no que diz respeito aos eixos: Reading, Writing, Listening e Speaking. E assim, colaborar também, para a compreensão dos problemas acadêmicos e epistemológicos inerentes a prática pedagógica, objetivando a superação das dificuldades que prejudicam o ensino e aprendizagem nas instituições educativas e consequentemente, na sociedade.

É essencial reafirmar a importância e a necessidade de utilizar as tecnologias a favor do ensino de Inglês. Claro que elas, por si só, não resolverão todos os problemas dessa disciplina, mas planejadas e inseridas nas aulas, possibilitarão a construção de uma ponte entre o ensino e as tecnologias, denominando- se tecnologias educacionais.

É pertinente considerar que a inserção dessas tecnologias deve ser acompanhada por metodologias que facilitem o processo didático-pedagógico, questionando-se sobre as competências do uso das tecnologias da educação, como: compreender a sua complexidade, refletir sobre a diversidade de fontes de informações, desenvolver a criticidade para conhecer sua origem e veracidade, identificar suas potencialidades e contribuições para articular saberes cotidianos, científicos, técnicos, sociais, emocionais, artísticos e estéticos. 
As tecnologias educacionais tornaram-se ferramentas de pensar e agir no ambiente escolar, de forma que incentivam a mobilização de atividades, em favor da melhoria das práticas pedagógicas e dos avanços nos resultados do trabalho docente e consequentemente, no ensino e aprendizagem do aluno.

Nesta perspectiva, as reflexões aqui propostas apontam que o desafio está lançado, com o propósito de modificar o processo de ensino e aprendizagem de LI, dentro do ambiente escolar, ascendendo questionamentos, diante das lacunas encontradas na formação inicial nos cursos de Letras/Inglês, bem como os desafios no espaço escolar. Essa responsabilidade, portanto, deve ser assumida por todos os envolvidos, tendo como foco, a formação dos professores educadores, principais agentes que contém a chave de abertura para o mundo letrado.

\section{REFERÊNCIAS}

ALMEIDA, Fernando José.; VALENTE, José Armando. Visão analítica da informática na educação no Brasil: a questão da formação do professor. Revista Brasileira de Informática na Educação, n. 1, p. 1-28, 1997.

ALMEIDA, Maria Elizabeth Bianconcini de.; RUBIM, Lígia Cristina Bada. O papel do gestor escolar na incorporação das TIC na escola: experiências em construção e redes colaborativas de aprendizagem. São Paulo: PUC-SP, 2004. Disponível em: <http://www.eadconsultoria.com.br/matapoio/biblioteca/textos_pdf/texto04.pdf >. Acesso em: 10 jun. 2016.

BRASIL. Lei Federal n 9. 394. Lei de Diretrizes e Bases da Educação Nacional. Brasília, DF: MEC, 1996.

BRASIL. Ministério da Educação. Secretaria de Educação. Parâmetros Curriculares Nacionais (PCNs). Língua Estrangeira. Ensino Fundamental. Terceiro e quarto ciclos. Brasília: MEC/FS, 1997.

BRASIL. Resolução CNE/CP $\mathbf{N}^{\circ}$ 1, de 18 de fevereiro de 2002. Institui Diretrizes Curriculares Nacionais para a Formação de Professores da Educação básica, em nível superior, curso de licenciatura, de graduação plena. Brasília, DF: MEC/CNE, 2002. Disponível em: <http://portal.mec.gov.br/cne/arquivos/pdf/rcp01_02.pdf〉. Acesso em: 10 jun. 2016.

BRITO, Glaucia da Silva.; PURIFICAÇÃO, Ivonélia da. Educação e novas tecnologias: um repensar. Curitiba: Ibpex, 2006.

CORACINI, Maria José Rodrigues Faria. O livro didático nos discursos da linguística aplicada e da sala de aula. In: CORACINI, M. J. R. F. Interpretação, autoria e legitimação 
do livro didático: língua materna e língua estrangeira. São Paulo; Campinas: Pontes, 1999, p. 17-26.

COSTA, Walison Paulino de Araújo. Percorrendo as imagens do livro didático de Língua Inglesa com vistas para além dos territórios nativos da anglofonia: uma análise de suas páginas de abertura. 2016. 216 f. Tese (Doutorado em Linguística) - Universidade Federal da Paraíba, Centro de Ciências Humanas, Letras e Artes, 2016. Disponível em: <www.rei.biblioteca.ufpb.br/jspui/bitstream/123456789/1029/1/WPAC18052016.pdf>.

Acesso em: 10 jun. 2016.

COUNCIL, British. O ensino de inglês na educação pública brasileira: elaborado com exclusividade para o British Council pelo Instituto de Pesquisas Plano CDE. 1. ed. São Paulo, 2015. Disponível

em: <https://www.britishcouncil.org.br/sites/default/files/estudo_oensinodoinglesnaeducacaopubli cabrasileira.pdf >. Acesso em: 10 jun. 2016

DEMO, Pedro. Educação e qualidade. Campinas: Papirus, 1994.

DEMO, Pedro. TICs e educação. 2008, p. 03-17. Disponível em: <http://www.pedrodemo.sites.uol.com.br>. Acesso em: 17 jun. 2010.

DIEUZEIDE, Henri. Tecnologia Educativa y desarollo de la educación. In: UNESCO - Ano Internacional de La educaion, ${ }^{\circ} 8$ CREFAL, 1970.

DIONÍSIO, Ângela Paiva. Livros didáticos de Português formam professores? Simpósios [do] Congresso Brasileiro de Qualidade na Educação: formação de professores. Brasília: MEC, SEF, 2002. Disponível em: <http://portal.mec.gov.br/seb/arquivos/pdf/vollb.pdf>. Acesso em: 10 jun. 2016.

FONTENELE, Lissa Mara Saraiva. Análise de materiais didáticos em inglês como LE: ideologia e relações de hegemonia. 2005. 169 p. Dissertação (Mestrado) - Universidade Estadual do Ceará, 2005.

FREIRE, Paulo. Política e educação. São Paulo: Cortez, 1997.

HOFFMAN, Jussara. Avaliação: mito \& desafio - uma perspectiva construtivista. Porto Alegre: Mediação, 2003.

LEITE, Tânia Azevedo. A seleção do material didático para o ensino de língua inglesa. 2003. Dissertação (Mestrado em Educação) - Universidade do Vale do Itajaí, 2003.

LIBÂNEO, José Carlos. Organização e gestão da escola: teoria e prática. Goiânia: Alternativa, 2014.

LIMA, Nayra Silva.; SILVA FILHO, Marcelo Nicomedes dos Reis. A abordagem comunicativa no processo de aquisição de língua inglesa. Web-Revista SOCIODIALETO, v. 3, n. 9, mar., 2013. 
MORAES, Maria Candida. Subsídios para fundamentação do programa nacional de informática na educação. Secretaria de Educação à Distância, Ministério de Educação e Cultura, 1997.

MORAN, José Manuel et al. Novas tecnologias e mediação pedagógica. 6. ed. Campinas: Papirus, 2000.

PAIVA, Vera Lucia Menezes de Oliveira e. O. Memórias de Aprendizagem de Professores de Língua Inglesa. Contexturas, n. 9, p. 63-78, 2006.

PERRENOUD, Philippe. Dez novas competências para ensinar. Porto Alegre: Artmed, 2000.

PIAGET, Jean. Psicologia e pedagogia. Tradução: Dirceu Lindoro e Rosa M. R. da Silva. Rio de Janeiro: Forence Universitária, 1970.

REINALDO, Maria Augusta Gonçalves de Macedo. Teoria e prática na formação do professor. Anais do II Congresso Internacional da ABRALIN (Curitiba), Fortaleza: UFC, v. II, p. 163-165, 2003.

TILIO, Rogério Casanovas. O livro didático de inglês em uma abordagem sóciodiscursiva: culturas, identidades e pós-modernidade. 2006. 258 f. Tese (Doutorado em Letras) - Pontifícia Universidade Católica do Rio de Janeiro, Departamento de Letras, 2006. Disponível em: <http://www.leffa.pro.br/tela4/Textos/Textos/Teses/Rogerio_Tilio_tese.pdf >. Acesso em: 10 jun. 2016.

VALLIN, Celso. Escola, projetos e novas tecnologias. Publicado em 2007. Disponível em: <http://www.escola2000.org.br/pesquise/texto/textos_art.aspx?id=69>. Acesso em: 20 nov. 2010 .

\section{Como referenciar este artigo}

SOUSA, Helenilson Ferreira de.; LIMA, Francisco Renato. Os desafios docentes e as contribuições das tecnologias educacionais no ensino e aprendizagem de língua inglesa: cenários contemporâneos. Rev. EntreLínguas, Araraquara, v. 4, n. 2, p. 218-235, jul./dez., 2018. E-ISSN: 2447-3529. DOI: 10.29051/rel.unesp.v4.n2.2018.10969

Submetido em: 21/01/2018

Revisões requeridas: 10/03/2018

Aprovado em: 20/06/2018 